\title{
OBSERVAÇÕES CRÍTICAS ACERCA DA NOÇÃO LEIBNIZIANA DE DECRETOS DIVINOS POSSÍVEIS*
}

Edgar Marques **

RESUMO Este artigo apresenta, em primeiro lugar, uma reconstrução conceitual das razões que levam Leibniz, em sua correspondência com Arnauld, a introduzir o conceito de decretos divinos possíveis. Em um segundo momento, o artigo desenvolve alguns argumentos para demonstrar que a introdução desse conceito torna inconsistente a arquitetônica global da metafísica leibniziana.

ABSTRACT This paper presents firstly a conceptual reconstruction of the reasons that lead Leibniz, in his correspondance with Arnauld, to introduce the concept of possible divine decrees. In a second moment, it develops some arguments in order to demonstrate that the introduction of this concept makes inconsistent the global architetonic of the leibnizian metaphysics.

Palavras-chave Leibniz, metafísica, liberdade, contingência, Deus.

* O presente artigo consiste em uma versão ligeiramente reelaborada de conferência apresentada em 12 de setembro de 2001, em Curitiba, no IV Colóquio Internacional de Estudos Filosóficos do Século XVII. Agradeço aos participantes do Colóquio as inúmeras objeções e observações feitas, que me permitiram realizar pequenas correções de curso. Este mesmo texto, já em sua versão presente, foi também apresentado e discutido no IX Colóquio Lógica e Ontologia, no dia 4 de outubro de 2001 na UFRGS, ocasião em que Ulysses Pinheiro, Luiz Henrique Lopes dos Santos e Lia Levy, dentre outros, criticaram severamente alguns dos pontos centrais de minha argumentação. Optei, entretanto, por publicar o texto em sua forma atual por não ter ainda clareza suficiente acerca do alcance e da validade das críticas apresentadas, esperando dar conta delas em publicações futuras.

* Departamento de Filosofia - UFMG 
A correspondência trocada entre Leibniz e Arnauld durante o ano de 1686, a partir do envio do primeiro ao segundo de um sumário de seu Discurso de Metafísica, consiste, grosso modo, em uma longa discussão travada basicamente acerca de três questões metafísicas relacionadas a decisivas posições defendidas por Leibniz no Discurso: (1) a possibilidade de se afirmar a tese de que a noção completa de uma substância individual contém em si a totalidade dos modos dessa substância sem incorrer, ao mesmo tempo, em um necessitarismo fatalista que implique a negação da idéia de que Deus e os homens são realmente - e não apenas ilusoriamente - livres; (2) o esclarecimento da relação subsistente entre alma e corpo; e (3) a inevitabilidade do recurso à noção de forma substancial para a constituição de uma compreensão metafísica mais adequada da realidade, apesar de ser essa noção perfeitamente prescindível - e até mesmo contraproducente - quando de uma descrição meramente física dos fenômenos.

As objeções relativas a esses pontos levantadas por Arnauld em suas cartas obrigam Leibniz a desenvolver seu sistema de modo a fornecer uma resposta satisfatória a elas, sendo, por esse motivo, a correspondência mantida entre ambos um locus privilegiado para a determinação do sentido e do escopo de certos conceitos leibnizianos fundamentais. Pretendo, no presente texto, restringir-me ao contexto da discussão da primeira questão acima esboçada, reconstruindo conceitualmente os problemas colocados por Arnauld que levam Leibniz a introduzir a noção de "decreto divino possível". Minha reconstrução assumirá, contudo, um caráter crítico, pois tentarei mostrar, em seguida, que essa noção é inconsistente nos quadros da arquitetônica global da metafísica leibniziana, o que seria um indicativo, caso eu tenha razão, de que a introdução dessa noção não soluciona de maneira aceitável as questões apresentadas por Arnauld. Não pretendo, no escopo do presente artigo, reconstruir e avaliar outras respostas que Leibniz tenha porventura desenvolvido para esse mesmo problema ${ }^{1}$, atendo-me única e exclusivamente a uma análise da solução que envolve o conceito de "decreto divino possível" e que se encontra presente na Correspondência com Arnauld.

Em carta de 13 de março de 1686, dirigida ao conde que intermediou o envio a ele do sumário do Discurso de Metafísica, Arnauld, contrariando as expectativas de Leibniz, rejeita enfaticamente o sistema metafísico leibniziano por considerar, dentre outros motivos não explicitados na carta, que do

1 Como, por exemplo, aquela que faz uso da distinção entre análise finita e infinita com objetivo de justificação do caráter contingente das ações humanas. 
artigo 13, segundo o qual o conceito individual de cada pessoa encerra tudo o que lhe ocorrerá, segue-se que a liberdade divina ficaria restrita à criação ou não do primeiro ser humano, pois decorreria dessa criação todo o desenvolvimento posterior da humanidade de modo necessário e fatalista, "uma vez que a noção individual de Adão encerrava que ele teria tantos filhos, e a noção individual de cada um de seus filhos tudo o que eles fariam e todos os filhos que eles teriam, e assim por diante. Não há, então, mais liberdade em Deus relativamente a tudo isso, supondo que ele tenha querido criar Adão, do que foi livre Deus, supondo que ele tenha querido me criar, para criar uma criatura incapaz de pensamento" 2 .

Arnauld considera, assim, que a tese da inclusão de todos os modos de uma substância individual na noção completa dessa substância implicaria em inevitável restrição da liberdade divina, pois a Deus caberia unicamente escolher entre a criação ou não do primeiro ser humano, seguindo-se desse ato de criação toda a história universal em marcha inexorável. Relativamente a Adão e a toda a sua descendência estaria Deus, portanto, limitado a optar simplesmente pela sua existência ou não, não subsistindo a possibilidade de que alguma interferência divina na criação pudesse alterar, mesmo que minimamente, sua configuração. A afirmação da tese da vigência de um vínculo intrínseco entre as substâncias individuais e seus modos teria por consequiência, dessa maneira, aos olhos de Arnauld, a adoção da idéia de que Deus não possui nenhum poder de ingerência na economia interna do mundo, não consistindo este último, então, em espaço no qual sua liberdade pudesse ser exercida.

O interessante a se destacar nessa objeção de Arnauld é que ele sustenta que, para que o arbítrio divino possa de alguma maneira ser exercido no mundo, deve haver um certo espaço de indeterminação, por assim dizer, na passagem da essência para a existência das substâncias singulares, de modo que a configuração do mundo possa ser vista como expressão da vontade divina, isto é, como produto de uma ação realizada por Deus. É precisamente esse espaço de indeterminação que seria subtraído por Leibniz ao afirmar a inerência dos modos às substâncias individuais. Esse espaço não deve, segundo ele, compreender a totalidade dos atributos das substâncias individuais, pois Arnauld concorda com a idéia de que Deus não legisla acerca do pertencimento ou não às substâncias dos atributos a elas essenciais -isto é, os atributos sem os quais elas não podem ser concebidas - , mas ele se recusa a aceitar que todos os atributos gozem desse mesmo estatuto. O perigo que adviria do sistema leibniziano seria, assim, o de uma homogeinização indevida do 
essencial e do acidental, que redundaria na transformação da criação divina em mera produção da existência de essências em si já absolutamente determinadas e por isso infensas a qualquer transformação.

A resposta de Leibniz ${ }^{3}$ a essa crítica de Arnauld compõe-se basicamente de quatro pontos diversos: o primeiro deles consiste na efetuação de uma distinção entre necessidade absoluta e necessidade hipotética. Leibniz rejeita o rótulo de necessitarista para o seu sistema por considerar que as relações afirmadas por ele entre as substâncias finitas individuais e seus modos, mesmo que intrínsecas, apenas podem se desenvolver sob a hipótese de serem essas substâncias criadas por Deus, o que introduziria um dado de contingência na efetivação dessas relações, pois tais relações somente se dariam caso Deus efetivamente criasse essas substâncias. Dessa maneira, seria incorreto classificar essas relações como sendo necessárias em sentido próprio.

O segundo ponto diz respeito à caracterização do modo da ação divina. Leibniz considera que o incômodo manifestado por Arnauld em relação à exclusão do espaço das configurações internas ao mundo criado do escopo de exercício da liberdade divina deriva-se de uma compreensão nitidamente antropomorfizante - e, portanto, inadequada — da maneira como se dá a ação divina. A idéia de que a liberdade de Deus ficaria limitada caso não se garantisse a possibilidade de uma sua intervenção no curso efetivo do mundo, alterando, assim, suas feições, baseia-se, segundo Leibniz, na falsa suposição de que Deus, tal como um de nós, age no tempo, e não na eternidade. Isto é, seria apenas por considerar, ainda que apenas tacitamente, que o agir divino se desdobra temporalmente, comportando reavaliações e novas intervenções frente a desenvolvimentos imprevistos e alterações conjunturais na face do mundo é que Arnauld poderia afirmar, de acordo com Leibniz, que Deus perderia em liberdade na hipótese de o desdobramento modal das substâncias individuais seguir-se da natureza interna dessas próprias substâncias, estando excluída aí a possibilidade de quaisquer interferências externas, mesmo que de Deus. A ação divina de criação efetiva-se, de acordo com Leibniz, ao contrário, fora do tempo, formando um todo articulado e unificado que compreende em si todos os atos de vontade referentes a todos os aspectos da criação. Quer dizer, a criação do mundo não deve ser confundida com uma mera criação do começo temporal do mundo, mas sim deve ser compreendida como criação, em um único ato, da totalidade do desdobramento espacial e temporal do mundo. Deus, sendo onisciente e possuindo um entendimento infinito, compreende, de um único golpe, a totalidade do curso do mundo a ser criado e, ao

3 Em duas cartas dirigidas ao Conde Ernst von Hessen-Rheinfels de 12 de abril de 1686, sendo que a primeira delas destina-se obviamente a Amauld. Ver: Leibniz, G.W., ibid., pág. 85-92. 
criá-lo, cria essa totalidade ${ }^{4}$. Seria, assim, em resumo, unicamente uma compreensão deficiente da natureza do agir divino que levaria, na visão de Leibniz, Arnauld a considerar que a tese veiculada no artigo 13 do Discurso implicaria em algum cerceamento da liberdade divina.

O terceiro ponto da réplica leibniziana a Arnauld envolve um esclarecimento acerca dos conceitos de indivíduo e de noção individual presentes no Discurso de Metafísica. As noções individuais leibnizianas caracterizam-se por serem plenamente individualizadoras, isto é, por possibilitarem a distinção dos objetos aos quais elas se referem não somente de todos os objetos existentes, mas também de todos os objetos possíveis. A noção individual de Adão presente no entendimento divino, por exemplo, deve possuir um grau tal de completude que seja possível diferenciar Adão não apenas de todos os outros sujeitos co-existentes no mundo real, mas também de todos os sujeitos passíveis de serem concebidos como sendo dele distinto, mesmo que aquilo que os diferencie do Adão em questão seja um mero detalhe quando contrastado com o pano de fundo de uma similitude massiva ${ }^{5}$. Possuindo as noções completas das substâncias individuais um "poder singularizador" tão absoluto, nada mais natural do que afirmar que a consciência do conteúdo intensional delas equivale ao conhecimento de tudo o que ocorrerá ao indivíduo por elas designado, sendo, assim, aos olhos de Deus, todas as proposições analíticas.

São razões de diversas ordens que levam Leibniz a assumir essa idéia de que deve haver noções completas absolutamente singularizadoras dos verdadeiros indivíduos. Seria possivel citar, dentre outras, sua adesão à noção de verdade como inclusão do predicado no sujeito, ou a sustentação de princípios tais como o da razão suficiente ou o da identidade dos indiscerníveis, sem que eu tenha contudo clareza suficiente acerca das relações internas subsistentes entre eles e possa indicar qual deles poderia ser tomado como mais fundamental em relação aos outros. Há, contudo, além dessas razões de natureza mais propriamente lógica, também razões mais afins à temática tratada neste artigo para a assunção do conceito de noção completa individual. No

4 "Il est peu digne de le concevoir (sous prétexte de maintenir as liberté) à la façon de quelques sociniens et corme um horme qui prend des résolutions selon les occurrences et qui maintenant ne serait plus libres de créer ce qu'il trouve bom, si ses premières résolutions à l'égard d'Adam ou autres renfemaient déjà um rapport à œe qui touche leur posterité, au lieu que tout le monde demeure d'accord que Dieu a reglé de toute etemitá toute le suite de l'univers, sans que cla diminue sa liberté em aucune manière. Il est visible aussi que cette abjection détache les volontés de Dieu les unes des autres, qui pourtant ont du rapport ensemble". Em: Leibniz, G. W., ibid., pág. 87.

5 "Car par la notion individuelle d'Adam, j' entends certes une parfaite représentation d' um tel Adam qui a de telles conditions individuelles et qui est distingué par là d'une infinité d'autres possibles fort semblables, mais pourtant différentes de lui (corme toute ellipse diffère du cercle, quelque approchant qu'elle soit)". Em: Leibniz, G. W., ibid., pág. 88. 
presente contexto, esse conceito é de capital importância, pois, para que se preserve, nos quadros da metafísica leibniziana, a liberdade do agir divino, é necessário que a ação de criação seja fruto de uma escolha de Deus entre alternativas efetivamente distintas umas das outras. No que toca aos indivíduos, essa distinção somente pode ser uma distinção entre indivíduos possíveis, uma vez que, por motivos óbvios, ela deve ser prévia à existência real dos indivíduos escolhidos para existirem. Mas, se é assim, então as noções dos indivíduos apresentadas ao intelecto divino devem ser absolutamente singularizadoras, pois caso contrário poderia ocorrer que dois indivíduos possíveis distintos satisfizessem a mesma noção individual, o que faria com que houvesse um inaceitável hiato de indeterminação entre a escolha divina e a efetiva criação de um determinado indivíduo, acabando por ser, em última instância, aleatório, e não um fruto da vontade divina, a determinação de qual dos dois viria a existir.

Vamos agora ao quarto ponto da resposta de Leibniz a Arnauld e que está intimamente ligado a esses dois últimos pontos.

Ao situar o agir divino na eternidade — e não no tempo —, concebendoo como uma escolha entre infinitos possíveis, Leibniz termina por compreender o mundo tomado como totalidade como sendo, ao fim e ao cabo, o verdadeiro objeto da escolha divina. Isto é, a escolha entre noções completas de substâncias individuais coincide, de acordo com ele, com uma escolha entre mundos possíveis, pois noções distintas de substâncias individuais implicam em mundos possíveis distintos. A liberdade divina é compreendida, então, como sendo exercida não através de algum tipo de intervenção no interior do mundo real criado, tal como, ao menos aparentemente, Arnauld o desejava, mas sim na escolha, realizada na eternidade, do mundo a ser criado dentre os infinitos mundos possíveis. O que Leibniz tenta tornar claro para Arnauld é, portanto, que as alternativas que se apresentam para a eleição divina não consistem em modos possíveis distintos de desenvolvimento do mundo já criado, o que pressuporia uma, para ele, inaceitável indeterminação intramundana, consistindo, ao contrário, em representações de conjuntos maximais de substâncias individuais compossíveis, isto é, representações de mundos possíveis.

Leibniz rejeita, assim, em suma, a acusação de que as proposições acerca das relações entre uma substância individual e seus modos seriam necessariamente verdadeiras sob a alegação de que verdades necessárias são unicamente aquelas que, por serem válidas em todos os mundos possíveis, independem da referência ao decreto divino particular da criação, o que exatamente não pode ser dito das proposições referentes a Adão e aos seus descendentes. 
A tréplica de Arnauld ${ }^{6}$ envolve basicamente a reiteração de que o que se encontra realmente em questão para ele é se as relações entre as substâncias individuais e seus modos tomadas em si mesmas — isto é, sem levar em conta se as substâncias individuais são afirmadas como reais ou caracterizadas como meramente possíveis — dependem ou não dos decretos livres divinos. O que estaria em jogo, então, não é se a existência efetiva das substâncias e seus modos é ou não dependente do decreto divino da criação, mas sim se as conexões intrínsecas subsistentes entre as substâncias individuais e seus modos é produto, de alguma maneira, da vontade divina. O que Arnauld deseja saber, em outras palavras, é se Deus modela, através de decretos que expressem sua vontade, as substâncias possíveis - e, por extensão, os mundos possíveis - por ele concebidas em seu entendimento, ou se essas conexões entre as substâncias e suas modificações independem absolutamente de algum decreto de Deus, sendo mais propriamente algo que simplesmente se apresenta ao entendimento e sobre o qual a vontade divina não possui nenhum poder de deliberação ou determinação, não sendo, portanto, essas conexões sob nenhum ponto de vista fruto de uma escolha ou ação divinas ${ }^{7}$.

O sentido da questão levantada por Arnauld consiste em forçar Leibniz a reconhecer que a tese da inclusão de todos os modos de uma substância individual em sua noção completa implica a independência absoluta das relações entre a substância individual e seus modos relativamente ao arbítrio divino, uma vez que a ação efetiva da criação é pensada como uma escolha entre possíveis, de tal modo que a "tomada de consciência" desses possíveis não pode ser vista como sendo ela mesma uma ação livre, mas sim como uma mera condição de possibilidade da ação. Se essa "consciência" dos possíveis independe da vontade divina, no sentido em que Deus simplesmente pensa o que pensa e não o que quer pensar, já que - e esse é um ponto importante o intelecto divino não se encontra submetido à vontade divina, então o pensamento dos possíveis não pode ser tomado como um espaço no qual Deus possa exercer sua liberdade. Mas, se for assim, esse parece ser o raciocínio de Arnauld, segue-se que, relativamente a Adão e a toda sua descendência, resta a Deus nada além da opção pela sua criação ou não, o que nos reconduziria ao estágio inicial de colocação da questão apesar de todos os esclarecimentos

\footnotetext{
Presente na carta de Arnauld a Leibniz de 13 de maio de 1686. Ver: Leibniz, G.W., ibid., pág. 94-100. Amauld escreve na carta de 13 de maio de 1686: "Il reste à demander (et c'est ce qui fait ma difficulté), si la liaison entre ces dojets ( $j$ 'entends Adam d' une part, et tout œ qui devait arriver tant à lui qu'à as postérité de l'autre) est telle d'elle-même, indépendamment de tous les décrets libres de Dieu, ou si elle en a été dépendante; c'est-à-dire, si œe n'est qu'en suite des décrets libres, par lesquels Dieu a ordonné tout ce qui arriverait à Adam et à sa postérité, que Dieu a connu tout œ qui arriverait à Adam et à sa postérité, ou $s^{\prime}$ il y a (indépendarment de ces décrets) entre Adam d'une part et ce qui est arrivé et arrivera à lui et à sa postérité de l'autre, une connexion intrinsèque et nécessaire". Em: Leibniz, G.W., ibid., pág. 96.
} 
feitos por Leibniz. Essa conclusão seria incompatível, consequentemente, com a concepção cristã, de acordo com a qual inúmeros acontecimentos internos ao nosso mundo - tais como alguns nascimentos e alguns milagres — são produtos de decretos divinos particulares ${ }^{8}$.

É precisamente no contexto da resposta a essa tréplica de Arnauld que Leibniz introduz o conceito de decreto divino possível. A estratégia seguida por ele na introdução desse conceito envolve a realização de dois passos distintos: em um primeiro momento ele afirma que sendo a existência das substâncias individuais finitas dependente de um decreto divino atual, então a possibilidade desse decreto divino deve estar de alguma maneira incluída na noção completa dessa substância. Quer dizer, que o decreto divino de criação de uma dada substância seja possível é uma das condições a serem satisfeitas para que essa substância mesma possa ser caracterizada como possível, pois se ela somente pode existir caso o decreto de sua criação seja efetivado, então uma condição para que ela seja possível é que esse próprio decreto também seja possível. As substâncias individuais criadas, portanto, apenas podem ser possíveis se a ação de sua criação também o for, o que faz com que sua possibilidade não seja absoluta, mas sim relativa à possibilidade do decreto divino que causa sua existência, caso essas substâncias realmente venham a existir. Com isso, Leibniz julga estabelecer um vínculo de dependência das substâncias individuais tomadas como possíveis relativamente a atos da vontade divina também tomados como possíveis - e não como atuais -, o que consistiria, ele o afirma, em uma espécie de meio termo entre as duas alternativas extremas colocadas por Arnauld ${ }^{9}$.

O que Leibniz parece querer dizer, creio, é que não somente a existência das substâncias individuais criadas não é necessária, mas sim — por mais estranha que essa afirmação possa aparecer — também que sua própria possibilidade não é necessária, quer dizer, que uma vez sendo sua existência

8 "Combien y a-t-il d'hormes, qui ne sont venus au monde que par des décrets très libres de Dieu, conme Isaac, Samson, Samuel et tant d'autres? Lors donc que Dieu les a connus conjointement avec Adam, ce n'a pas été parce qu'ils étaient enfermés dans la notion indivicuelle de l'Adam possible, indépendarment des décrets de Dieu. Il n'est donc pas vrai que toutes les personnes individuelles de la postérité d'Adam possible, puisqu' il aurait fallu qu'elles y eussent été enfermées indépendarment des décrets divins". Em: Leibniz, G.W., ibid., 96-97.

9 "... on ne saurait nier qu' il n'y ait véritablement une telle notion pleine de l'Adam accompagné de tous ses predicats et conçu comme possible, laquelle Dieu connaît avant que de résoudre de le créer, corme vous semblez accorder; autrement il résoudrait avant de connaître assez. Je crois donc que le dilerme de la double explication que vous proposez reçoit quelque milieu et la liaison que je conçois entre Adam et les événements humains est intrinsèque, mais elle n'est pas nécessaire indépendamment des décrets libres de Dieu, parce que les décrets libres de Dieu, pris corme possibles, entrent dans la notion de l'Adam possible, ces mêmes décrets devenus actuel étant la cause de l'Adam actuel. Je demeure d'accord avec vous contre les cartésiens, que les possibles sont possibles avant les décrets de Dieu actuels, mais non sans supposer quelquefois les mêmes décrets pris corme possibles", em: Leibniz, G.W., ibid., pág. 116. 
dependente de uma ação efetiva de Deus, então a possibilidade dessa existência — isto é, o ser possível — dependerá da possibilidade dessa ação, não se colocando como mero produto de uma consistência interna dos traços característicos dessas substâncias presentes nas representações delas que aparecem ao intelecto divino. É como se as substâncias individuais criadas fossem duplamente dependentes da vontade divina: da vontade real para efetivamente existirem, e da vontade possível para serem tomadas como possíveis. Dessa maneira, mesmo sendo intrínsecas as conexões entre uma substância individual e seus modos, a possibilidade dessa substância não decorrerá única e exclusivamente da coerência apresentada por essas conexões, senão que dependerá também diretamente da possibilidade — e, repito, não da efetividade - do decreto divino de sua criação. Dito de outro modo, o que ocorre é que para pensar qualquer modificação de uma substância individual como sendo possível, Deus não pode se ater aos limites da representação mesma dessa substância, senão que ele tem de representar para si mesmo o ato de vontade possível pelo qual ele próprio cria essa substância, uma vez que somente se esse ato for possível essa substância também o será. Diferentemente do que acontece no caso das verdades necessárias e eternas, no qual não é preciso levar em conta a ação divina de criação de um determinado mundo em função do fato dessas verdades serem válidas em todos os mundos possíveis, no caso das verdades contingentes é preciso que se lance mão de uma representação do decreto divino de criação do mundo em questão. É por isso que Leibniz pode afirmar, em seu texto Verdades necessárias e verdades contingentes, provavelmente contemporâneo ao Discurso de Metafísica, que "enquanto as verdades necessárias envolvem unicamente o entendimento divino, as verdades contingentes envolvem os decretos da vontade" ${ }^{\circ}$.

O segundo passo da resposta de Leibniz a Arnauld envolve a afirmação de uma relação de dependência entre as substâncias individuais e os decretos divinos possíveis de uma natureza um pouco distinta da acima apresentada. Não se trata agora simplesmente de destacar o fato de que a causa da existência das substâncias deve ser possível para que essas substâncias mesmas sejam possíveis, mas antes de sublinhar que as substâncias possíveis pertencem a um conjunto maximal de substâncias e de fenômenos compossíveis — isto é, pertencem a um mundo possível —, o qual é ordenado por certos decretos divinos primitivos que estabelecem, por assim dizer, as leis e os fins próprios a cada um desses mundos. Na medida em que as noções completas das substâncias individuais exprimem à sua maneira a totalidade do mundo ao qual 
pertencem, essas leis fundamentais, que expressam os desígnios divinos relativos a esse mundo, determinam essas próprias noções completas, pois não é a totalidade de um mundo que é tornada compatível com um determinado indivíduo previamente pensado, mas sim o indivíduo que é concebido a partir dos desígnios e fins que orientam também essa concepção do mundo. O preestabelecimento da harmonia interna aos diversos mundos possíveis decorre, então, do fato de que as substâncias individuais que compõem esses mundos são concebidas em consonância com os desígnios e fins a partir dos quais Deus pensa cada um desses mundos. Nas palavras de Leibniz: "cada mundo possível depende de alguns desígnios principais ou fins de Deus que lhe são próprios, quer dizer, depende de alguns decretos livres primitivos (concebidos sub ratione possibilitatis) ou leis da ordem geral daquele dos universos possíveis ao qual elas convém e do qual elas determinam a noção, tanto quanto determinam a noção de todas as substâncias individuais que devem entrar naquele universo. (...) Assim, todos os eventos humanos não poderiam deixar de ocorrer como eles efetivamente ocorreram, supondo que tenha sido feita a escolha de Adão. Mas não tanto por causa da noção individual de Adão, ainda que essa os inclua, mas por causa dos desígnios de Deus, que entram também na noção individual de Adão e que determinam a noção de todo o universo e em seguida tanto a noção de Adão quanto as noções de todas as outras substâncias individuais desse universo"11.

Resumindo, em resposta a Arnauld, Leibniz enfraquece, por assim dizer, a independência, relativamente à vontade de Deus, das conexões intrínsecas entre as substâncias individuais e seus modos através da consideração de que (a) a possibilidade das substâncias individuais pressupõe a possibilidade do decreto divino de sua criação e (b) que a constituição da noção completa das substâncias individuais envolve a consideração dos decretos divinos possíveis referentes às leis e fins fundamentais dos mundos aos quais essas substâncias pertencem.

Com essa resposta, Leibniz consegue, aparentemente, tanto ampliar o campo de atuação da vontade divina, esboçando a imagem de um Deus que modela por meio dos decretos possíveis de sua vontade substâncias e mundos possíveis, quanto garantir o caráter contingente das proposições predicativas referentes a substâncias individuais em função da dependência dessas substâncias relativamente aos decretos possíveis primitivos da vontade divina.

Não considero, entretanto, que Leibniz tenha atingido nenhum desses dois objetivos através da introdução do conceito de decreto divino possível. Creio que esse conceito é obcuro sob diversos pontos de vista e que, além disso, é 
incompatível com certos aspectos da metafísica leibniziana. Creio também que Leibniz já tinha apresentado a Arnauld uma resposta mais satisfatória para o problema do escopo da liberdade divina e que, portanto, de certa maneira, acaba, ao lançar mão da idéia de decreto divino possível nesse contexto, por se comprometer desnecessariamente com um conceito problemático.

O que está em jogo inicialmente no debate entre Leibniz e Arnauld é a delimitação do campo no interior do qual Deus pode agir livremente. A sugestão de Leibniz é, como vimos, a de que ampliamos a liberdade divina ao considerarmos que decretos divinos possíveis estão contidos nas noções completas das substâncias individuais. Ora, uma vez que o que se compreende por liberdade, nesse contexto, é a possibilidade ou capacidade de determinação da própria ação através da própria vontade, somente podemos falar de uma ampliação da liberdade divina caso possamos falar da realização efetiva de ações divinas implementadas a partir da vontade divina. E é exatamente isso o que não me parece ser o caso aqui.

Se examinamos mais detidamente o conceito de decreto divino possível, observamos que o recurso a ele não amplia de maneira nenhuma o campo de implementação efetiva da vontade divina, pois um decreto divino possível simplesmente não consiste em um ato da vontade divina, mas sim, mais propriamente, em uma representação que se apresenta ao entendimento divino e cujo conteúdo intensional é uma possível ação fundada na vontade divina. Quer dizer, ao refletirmos acerca do estatuto ontológico dos decretos divinos possíveis, vemos que eles, por uma questão de princípio, não podem ser caracterizados como decretos atuais da vontade de Deus, restando unicamente que eles sejam uma representação presente no entendimento divino, como de resto, aliás, o são todos os possíveis, de acordo com Leibniz ${ }^{12}$. Decretos divinos possíveis são, para falar explicitamente, representações atuais no entendimento divino e é esse seu estatuto de ser.

Isso implica, contudo, que Deus, ao conceber ações suas possíveis, não está deliberando nem agindo de nenhuma maneira, mas sim está unicamente pensando, sem que os conteúdos dessas representações pensadas possam ser produto de uma ação realizada com base em sua vontade. Desse modo, uma vez que, para Leibniz, os conteúdos intensionais presentes ao intelecto divino não são determinados pela vontade divina - caso contrário as verdades eternas estariam sujeitas ao arbítrio de Deus —, então fica claro, creio, que a constituição desses conteúdos não é um espaço no qual a liberdade divina seja de alguma forma exercida. 
Faz todo sentido, a meu ver, afirmar que Deus é livre porque faz o que quer, possuindo ele em seu entendimento uma representação daquilo que ele quer e que acaba por ser o objeto de sua eleição. Isto é, faz sentido considerar que Deus seja livre ao fazer o que quer desde que aquilo que ele quer seja algo que se apresente a ele independentemente desse querer particular que ocasiona essa ação, pois, caso contrário, ele não teria como determinar o objeto dessa vontade. Não faz sentido, entretanto, considerar que Deus possa ser livre por pretensamente querer pensar o que ele pensa - isto é, por amoldar de alguma maneira as noções completas das substâncias individuais possíveis por meio de seus decretos divinos possíveis - , uma vez que é necessário alguma representação daquilo que se quer pensar para que se possa identificá-lo como sendo precisamente aquilo que se quer pensar e se queira efetivamente pensá-lo. Deus somente poderia pensar o que quer pensar caso sua vontade pudesse determinar os conteúdos de seu pensamento, mas a questão é que não haveria como ele determinar, por sua vez, o conteúdo dessa sua volição - isto é, o que ele quer pensar e que passaria a ser por ele pensado senão que por meio de uma representação do entendimento. Quer dizer, se Deus, por exemplo, quer pensar em X, então é necessário que ele tenha uma representação qualquer de $X$ para que ele possa determinar que é em $X$ que ele quer pensar, e não em Y. Mas se é assim, então ele tem de pensar em X para que ele possa querer pensar em $X$, o que faz com que o conteúdo do pensamento em X independa logicamente da vontade de pensar em X. Desse modo, pelo fato da vontade se aplicar a um objeto definido independentemente dela, seria um contrasenso atribuirmos a Deus o poder de determinar os conteúdos intensionais de seus pensamentos por meio de sua vontade.

Mas, mesmo se relevarmos essa questão relativa ao estatuto dos decretos possíveis e os tomarmos - incorretamente, reafirmo - como atos - possíveis - da vontade divina, há, contudo, um outro problema, talvez de maior monta, referente a essa atribuição mesma de possíveis a Deus, quaisquer que eles sejam. Receio que a diferença ontológica entre Deus e as substâncias individuais finitas seja de uma natureza tal que venha a ser contrasensual a consideração de possíveis a ele atribuídos. Senão vejamos.

Falar em substâncias individuais finitas possíveis é falar em representações presentes no entendimento divino que possuem como conteúdo intensional modelos de substâncias individuais logicamente consistentes, cuja existência não depende dessas próprias substâncias, mas sim de um decreto divino de criação. A consistência lógica interna é, assim, condição necessária e suficiente da possibilidade dessas substâncias, mas apenas condição necessária - e não suficiente - da sua existência. Suspeito que o estatuto da mera possibilidade esteja intrinsecamente ligado a essa, digamos, "precariedade de 
ser" característica das substâncias criadas, mostrando-se, assim, como sendo, no mínimo, problemática a aplicação dessa noção a uma substância que seja caracterizada precisamente como causa de si mesma, isto é, como sendo um ente de cuja essência a existência se segue sem que o concurso de outros fatores seja requerido.

As substâncias individuais finitas possíveis são pensadas no interior do quadro dos mundos possíveis, isto é, elas são pensadas como elementos de conjuntos maximais de substâncias individuais cuja existência é mutuamente compatível. Quando falamos, por exemplo, de Adãos possíveis, estamos falando de substâncias individuais pertencentes a mundos possíveis distintos e que, dessa maneira, nunca poderiam coexistir, estando cada uma delas, por assim dizer, como que enclausurada ao mundo ao qual pertence. Esses mundos possíveis, formados cada um por substâncias individuais compossíveis, por sua vez, excluem-se mutuamente, pois o caráter maximal de cada um deles impede a existência efetiva de mais de um mundo possível. O que torna, então, razoável a afirmação de que há vários mundos possíveis é exatamente o fato de esses não virem a existir por si mesmos, permanecendo como meras representações atuais no intelecto divino, uma vez que, caso não fosse desse modo, eles impediriam mutuamente a existência. A pluralidade dos mundos possíveis é preservada, assim, porque da possibilidade deles não se segue imediatamente sua existência, sendo essa pluralidade, em última instância, uma pluralidade de representações de mundos e não de mundos propriamente ditos.

A situação é radicalmente distinta quando passamos a falar não mais em substâncias individuais finitas possíveis e mundos possíveis, mas sim aplicamos a idéia de possibilidade à própria substância infinita e falamos de coisas tais como decretos divinos possíveis. Em função do princípio da identidade dos indiscerníveis e da tese super-essencialista de individuação das substâncias pela totalidade de seus modos, somos forçados a admitir que a introdução de decretos divinos possíveis distintos implica a introdução da idéia de substâncias infinitas distintas — isto é, de deuses possíveis distintos —, pois o Deus que cria um determinado mundo possível não pode ser idêntico ao Deus que cria um outro mundo possível distinto do primeiro, uma vez que eles realizam ações diversas. O problema é que, diferentemente das substâncias individuais finitas, os deuses possíveis, e aqui sigo com certa liberdade a argumentação desenvolvida por Margaret Wilson em seu artigo Possible $G_{o d s}{ }^{13}$, não podem ser como que encerrados no interior das noções comple- 
tas dos mundos possíveis e tratados como meros entes possíveis, pois, de acordo com o argumento ontológico leibniziano, sendo isenta de contradições a noção de um ser absolutamente perfeito, a existência desse ser seguese imediata e necessariamente.

Seríamos levados, então, em um único movimento, da atribuição do caráter de possibilidade a decretos divinos à afirmação da existência efetiva de infinitos deuses, uma vez que tais decretos possíveis determinariam deuses possíveis distintos e cada um desses deuses existiria necessariamente, pois a natureza de Deus é tal que sua existência decorre de sua essência. Teríamos, além disso, o problema da determinação do estatuto ontológico dos diversos mundos, já que a existência de cada um desses deuses implicaria a existência do mundo criado por ele. Sendo cada um desses mundos maximal e sendo todos eles mutuamente excludentes, não parece fazer sentido no interior da metafísica leibniziana a idéia de que todos os mundos possíveis realmente existem.

O equívoco fundamental que se encontra na origem de todas essas dificuldades consiste na idéia de que a noção completa de cada mundo possível deve incluir o respectivo decreto divino possível de sua criação. A aceitação dessa idéia acaba por gerar a dependência da possibilidade dos mundos da possibilidade dessa ação divina, o que leva, a meu ver, à extrapolação do campo legítimo, dentro do sistema leibniziano, de aplicação da idéia de mera possibilidade. Nas substâncias criadas pode haver a não- atualização do que é potencial - elas podem, por exemplo, nunca vir a existir por não serem criadas -, mas não na substância infinita e criadora. Em função do "curtocircuito" que há, em Deus, por ele ser causa de si mesmo, entre essência e existência, creio ser impossível a atribuição a ele de qualquer tipo de possibilidade que não redunde imediatamente em efetivação dessa possíbilidade.

Além disso, uma ação divina não pode ser tomada por um elemento interno a um mundo possível — isto é, uma possibilidade ao lado de outras possibilidades - , pois ela tem por objeto exatamente a totalidade desse mundo e ela não pode ter a si mesma como objeto ao qual ela se aplica. Ao escolher o mundo a ser por ele criado, Deus estaria escolhendo, assim, também a ação de criação que ele gostaria de realizar, o que faria com que a vontade de criar um determinado mundo tivesse como pressuposto a própria vontade de criar esse mundo, e assim ao infinito.

Do mesmo modo, a concepção de Deus adotada por Leibniz também parece impedir que possamos considerar que Deus, ao conceber, incluído na noção completa de um mundo possível, seu próprio decreto possível de criação, esteja pensando a si mesmo sub ratione generalitatis - isto é, levando em conta apenas algumas de suas características definidoras e não o conjunto 
delas - , pois Deus, diferentemente dos seres humanos, possui um conhecimento perfeito de sua própria natureza, sabendo de forma absoluta as ações que são compatíveis com sua própria natureza e as que não o são.

O que há de irônico nessa história é o fato de a resposta anterior de Leibniz a Arnauld conter elementos que possibilitam a formulação de uma concepção que não incorre, ao menos aparentemente, nos problemas apontados — o que não significa, obviamente, que ela não incorra em outros problemas -. Vejamos, em traços largos, quais seriam as características fundamentais dessa concepção.

Podemos considerar que Deus exerce sua liberdade ao escolher, com base unicamente em sua vontade, dentre os infinitos mundos possíveis representados em seu entendimento, aquele mundo que será criado, e que "ser possível”, nesse caso, significa simplesmente apresentar consistência lógica interna, sem que tenhamos de fazer nenhuma referência a possíveis ações divinas. "Ser possível" é uma característica, portanto, atribuída aos mundos em função de sua própria natureza e não em função de uma relação qualquer que eles estabeleçam com Deus. Para que eles possam ser objetos de uma possível escolha divina é preciso que eles já se apresentem ao intelecto divino como possíveis, o que faz com que seja circular a idéia de que essa sua possibilidades esteja fundada na possibilidade do decreto. Dito de outro modo, mundos possíveis são possíveis em si.

Deus age livremente ao escolher um dos infinitos mundos possíveis para ser criado, e cada um desses mundos é constituído por substâncias individuais que espelham a totalidade do mundo ao qual pertencem e que, portanto, existem exclusivamente em um único mundo. A escolha de Deus dá-se, dessa maneira, entre conjuntos maximais de substâncias compossíveis - isto é, entre mundos possíveis —, os quais não comportam nenhum tipo de alteração interna em função da vontade divina. Isto é, Deus pode escolher entre criar ou não criar um mundo possível, mas não pode optar por uma sua modificação, pois qualquer alteração relativa à representação original implica a criação não do mundo original modificado, mas sim de um outro mundo distinto do primeiro. Uma vez que Leibniz adota a tese super-essencialista, segundo a qual a individuação se dá pela totalidade dos atributos, não há como conceber a "modelagem do mundo" reivindicada por Arnauld e aparentemente satisfeita por Leibniz por meio da noção de decreto possível.

Mas, não teríamos, então, ao fim e ao cabo, simplesmente retornado ao ponto de partida expresso na primeira indagação de Arnauld? A liberdade 
divina face a Adão, para seguirmos com nosso exemplo, não estaria restrita às opções de criá-lo ou não?

Creio que não necessariamente. Julgo que podemos encontrar uma saída através da consideração de que são infinitos os mundos possíveis que se apresentam ao intelecto divino. Mesmo que Deus não possa modelar a noção completa de Adão de acordo com sua vontade, Deus não está condenado a simplesmente, por assim dizer, aceitá-lo ou recusá-lo em bloco, pois ele concebe também infinitos mundos nos quais há indivíduos extremamente semelhantes a Adão sob vários aspectos e que dele se diferenciam por alguns atributos e relações. Com uma certa liberdade terminológica, a qual Leibniz também concede a si mesmo ${ }^{14}$, podemos falar de vários Adãos distintos, os quais seriam como que representações diversas de Adão. Trata-se, para falar de uma maneira mais apropriada, da representação de Adão sub ratione generalitatis.

Quero crer que essa concepção acima esboçada fornece elementos suficientes para pensarmos em uma ação divina de criação que nada fica a dever em termos de alternativas de escolha àquela que inclui o conceito de decreto divino possível. Apesar de Deus não poder modelar a noção completa de Adão ele nada perde em termos de possibilidade de escolha, pois estão presentes em seu intelecto infinitas representações que correspondem a todos os resultados possíveis de um tal processo de modelagem. Isto é, seu intelecto já lhe apresenta representações que abrangem a totalidade daquilo que seriam as variações possíveis de cada substância individual, cabendo à sua vontade a determinação de qual delas será escolhida para existir. Dessa forma, Leibniz não precisaria recorrer ao conceito de decreto divino possível para responder, em seus próprios termos, às indagações postas por Arnauld.

14 "en parlant de plusieurs Adams, je ne prenais pas Adam pour un individu déteminé, mais pour quelque personne conçue sub ratione generalitatis sous des circonstances qui nous paraissent déterminer Adam à un individu, mais qui véritablement ne le déterminent pas assez: corme lorsqu' on entend par Adam le premier harme que Dieu met dans un jardin de plaisir dont il sort par le péché, et de la côté de qui Dieu tire une ferme", em Leibniz, G.W., Discours de métaphysique et correspondance avec Arnauld, Vrin, Paris, 1993, pág. 119. 